\title{
His Bundle Pacing
}

Editors

PRAMOD DESHMUKH

KENNETH A. ELLENBOGEN

\section{CARDIAC \\ ELECTROPHYSIOLOGY CLINICS}

www.cardiacEP.theclinics.com

Consulting Editors

RANJAN K. THAKUR

ANDREA NATALE

September 2018 • Volume 10 • Number 3 